\title{
Role of Spirituality in Watershed Management and Natural Capitalism
}

\author{
Ankush Mala Chalise \\ (Dept of Journalism and Mass Communication/Andhra University, India)
}

\begin{abstract}
Hinduism believes that almighty created this universe on water mass; the basis for all living and non living product. Water is a pious element in the Hindu culture which is worshipped and highly respected. Despite of having this spirituality, rivers that are considered holy is degrading considerably in terms of its cleanliness and also holiness. Numerous projects and plans are implemented to conserve them but the bizarre situation still prevails. Government and donor agencies are adopting natural capitalism and inclusive green growth path to address the water security but the output is limited on paper documents. Water resource management is subject of social engineering than civil engineering. The better and cheapest method to manage water pollution is dilution and watershed approach can be appropriate on this method. Individual behavior and social culture related with water security is worsened than earlier. The root cause behind is absence of spiritual component on pillars of natural capitalism. Fear and fence approach on water security may cause additional cost thus self motivation in people could be fruitful in solving this problem. Spiritual approach on water resource management may prove its efficiency especially to manage quantity and quality of holy rivers such as Ganga. This paper focuses to emphasize the key role of spirituality that can play an effective role on managing the water sources by changing the behavior and attitude in people.
\end{abstract}

Keywords: attitude change, Hinduism, natural capitalism, spirituality, watershed management,

\section{Introduction}

"Annād bhawantī bhutanī prajanyāddanna sambhawa
yegyād bhawanti prajanyo yegya karmasamudbhawa"

- Bhägawat gitā

This is the message of Bhägawat gita and center theme of Sanätan dharma, which summarizes that water is vital for all living beings and every element on Earth. Animal kingdoms are modified mass of plant product that is possible in the presence of water. Precipitation is the source of fresh water so all green business, "Yagna" is spiritutal language should be centered on sustainable water source management.

Around the world, we are all becoming more aware of water concerns, often through news stories about the effects of climate change such as floods, droughts and rising sea levels. Water, and the issues that surround its use, are complex, too complex for anyone to address in isolation. But they can be simplified into three broad areas: we either have too much water (floods), too little water (droughts), or water that is too bad (poor quality, pollution). But within these areas there are so many crosscutting trade-offs, challenges and emotional responses that the search for solutions is fascinating yet so complicated that it is paralyzing to grapple with at the same time.

In Nepal water systems are not only essential for life, but also a source of livelihood for innumerable nature-based communities that depend on forests, land, coasts, river basins and other natural resources. Unlike people in cities, they are directly dependent on rivers and other water sources for their livelihood. Water-based communities are comprised of Majhi, Bote, Kumal and Darain of the plains and hills areas who are struggling and resisting defending their rights over water resources, often facing the worst impacts of the modernization and development processes. Water system of this region is in crisis and the situation will only worsen in the coming decades. The region is facing a reduction in its clean water resources due to the intensive and unplanned exploitation of groundwater, industrial and mining activities, the construction of large numbers of power project, increased water contamination, and factors relating to climate change. At the same time, it is experiencing an unprecedented increase in the demand for water due to a growing and urbanizing population, unfettered economic growth, and an explosion in water-intensive industries. Marginal people are on trouble and many people of lower middle class are migrating to new area with tag of registered poor. They are not included on value chain nor on sustainable supply chain. They are included on chain of speculative business as end consumer and primary producer, who contribute on profit and primary means of production. 


\section{Need of Spirituality in Natural Capitalism}

"Inclusive green growth is the pathway to sustainable development". This is the slogan identified presently by World Bank group and many other bi-lateral organizations as their visionary action. The concept largely based on natural capitalism. This concept way adds to the chorus started by the Organization for Economic Co- operation and Development (OECD) and United Nations Environment Program (UNEP), supporting the idea that "inclusive green growth is good economics and good development policy" . This concept looks very sound in favor of poor, but if we examine the service delivery ratio and return on investment, the effectiveness of such projects can be questioned. Though the concept of natural capitalism is praiseworthy, implementation becomes doubtful without the incorporation of spirituality. In the society like ours, spiritual belief is of prominent importance, hence the role of almighty in natural capitalism can have more practical implications

Natural capitalism might be incomplete without spiritual capitalism.. Though we do not have clear technology to measure the value of ecosystem, we percept this as a valuable and integral component of our life system. Likewise, the value of spiritual action is a subject of perception. For instance, a statue made with same matters, one is of God figure and the other of animal, the former one has higher importance as a result of the emotional and spiritual perception. This difference is the subject of spiritual capitalism, which can add value to make the product more distinct and priceless. Ordinary accountant fails to predict the real value of nine primary source of capital (Earth, Water, Fire, Air, Sky, Filling, Soul, Time and Location) as described on Baiśsesik Darśan. They can measure the associated cost to add value on them. Identification and pricing of capital base as cause capital and effect capital is necessary to determine the price of the spiritual services, which is beyond the capacity of traditional accounting practices. Nature is simulated result of series data of spiritual action, where almighty God is software designer. We are using this software on free of cost. Likewise a software user may not know the spirit of programmer, supporter of natural capitalism may not understand the spirit of almighty God. Present accounting practice could not identify the real owner and/or donor of those capital bases, because the subject is related with spirituality rather than natural science. Almighty God had not tagged the price for them, nor there limitation to utilize them. The way to utilize them determines sine or salvation rather than accounting profit or loss. As such, neglecting spiritual capital, like neglecting human and physical capital, is simply bad management, bad economics, and bad for growth. Hence inclusive green growth could be pathway to spiritual development, where balance between sustainable water and spiritual entrepreneurship growth will be the centre goal.

\section{Basis for Individual Behaviour}

The value perception of natural as well as spiritual capital is determinant of individual behavior. In practice, individuals make decisions in a variety of ways: "by the head" (based on calculation), "by the heart" (based on emotion), and "by the book" (based on rules) (Weber and Lindemann 2007). There are four types of behavioral biases. First, "cognitive myopia" prevents people from accurately balancing future benefits and immediate costs and from assessing the desirability of reductions in immediate benefits in exchange for future gains (Ainslie 1975). Second, individuals are inconsistent in their treatment of time (Ainslie 1975): they apply high discount rates to costs and benefits that will occur at some point in the future, discounting much less when both time points are in the future and one occurs later than the other, in a kind of "hyperbolic discounting." These biases explain why it is difficult to implement policies that entail immediate costs but future benefits even if the result is a net (discounted) gain. A classic example is the failure of consumers to buy more energyefficient appliances even when future energy savings would more than compensate for higher up-front purchase costs (Gillingham et al. 2009). Third, individuals suffer from "loss aversion", that is, they weigh losses more than gains, evaluating both relative to a reference point (Tversky and Kahneman 1992). If individuals use the current situation as the reference point, they will consider the cost of environmental policy as a loss and weigh it more heavily than the gain (averted environmental damages). If the reference point is the future, when the loss is the environmental destruction, they will weigh it more heavily than the gain (Weber and Johnson 2012). Fourth, individuals have an aversion to ambiguity, which causes them to delay making decisions (Tversky and Shafir 1992). Aversion to ambiguity is particularly problematic for environmental issues, such as climate change, that involve huge uncertainties: while it disappears if decision makers regard themselves as expert in a domain (Heath and Tversky 1991).

During this period, attention to non-material values all but vanished, even though cultural values had been drivers of the modern conservation ethic (Nash 1982; Lord 1994; Adams 1996) and individual interest is strongly associated with aesthetic, ethical and spiritual values. While the role of cultural values in building support for conservation was noted in the 1980s (McNeely and Miller 1984; Brownrigg 1985) and the concept of protecting diversity rather than “... some ideal, pristine nature” was recognized (Soule and Kohm 1989, 2), both were largely ignored in practice (Infield 2001). The past decade, however, has seen recognition of the interrelationships between culture and conservation (Maffi 1999, Posey 1999) and initiatives to re-integrate 
cultural values into conservation. Researchers and conservation practitioners alike are recognizing that conflicts with local groups increase when local cultural values are ignored (Verschuuren 2007), contributing to failures to conserve biodiversity, and undermining local peoples' abilities to help protect their environment (Alcorn 1993).

Different behavioral changes can be triggered by different learning processes; such as learning by being hurt, being told, and observing and imitating (Weber and Johnson 2012). This principle is applicable to predict the market behavior. With critical observation, we find that economic analysis rely on an excessively narrow view of human motivation, which may vitiate secular attempts to aid development. A blend of spiritual understanding and economic insight is needed for a genuine transformation of the lives of the people to take place (Davis 2007).

\section{Concept of four windows on water resource management}

Arguments for a cultural approach to conservation address two questions. First, "What are the values we wish to conserve?" This reflects concerns over the narrowness of perspectives expressed in current conservation theory and practice, helps clarify the non-material objectives of conservation, and contributes to the evolution of new conservation approaches. Second, "How can we achieve conservation?" This question speaks to the fact that the biological diversity that defines current conservation objectives continues to decline (Yamin 1995), demonstrating the need for new approaches that will improve conservation delivery. The integration of cultural perspectives into mainstream conservation practice will require examination on a sectorby-sector and case-by-case basis to determine which values can, and importantly cannot, be integrated into specific conservation initiatives.

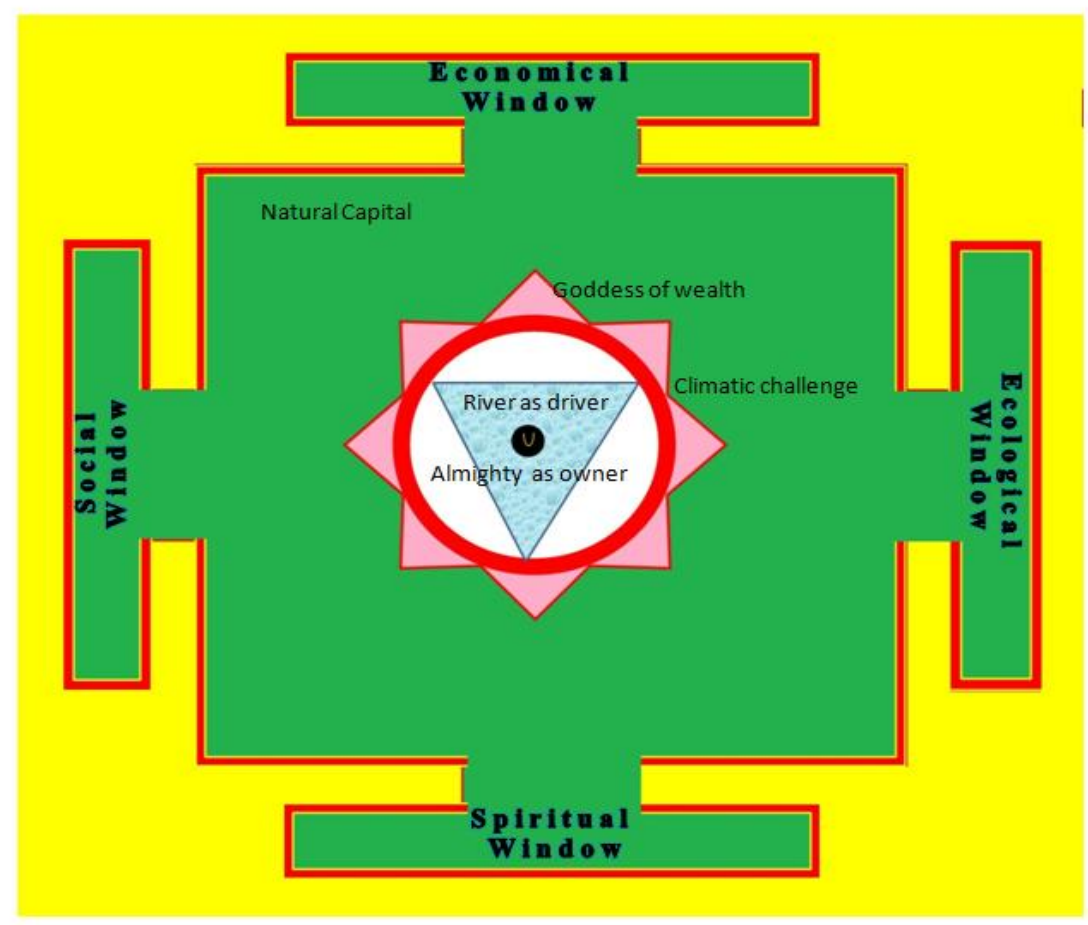

Four windows of inclusive water resource management

There are four different windows to observe the capital; economical, ecological, social and spiritual. While traditional accounting measures capital on monitory value with economical window, measurement from spiritual window is a subject of belief. Market behavior of people depends on the window they use to evaluate the capital, and strategies to accumulate them. People who use economical window only calculate present value of returns without considering the others welfare. Similarly, people willing to use spiritual window on the other hand do not consider the accounting benefit and cost. World of spirituality is meaningless when one looks from economical window but material achievement is less significant when observed from the spiritual. To maintain the balance between economy and spirituality is the task of social and environmental window. Natural capitalism comes from three windows, economical, ecological and social and often discards the spiritual window. As a result, our rivers, forests and other natural resources are dismantled and corrupted. With the blend of these four mixtures, we can expect to add the value to our water sources and also incept the concept of self motivation to preserve as well as utilize them. 


\section{Why policies that are made to protect the watershed fails?}

Policies are made, in national as well as international level to preserve and protect the water sources. There are laws to maintain the tributaries of international rivers. Despite of those laws, rivers of Nepal are adding pollutant to National River Gangāa. Though Government of India had given top priority to manage this holy river, but they are not able to warn Nepal government to stop the river pollution. All rivers of Nepal are tributaries of holy Gang $\overline{\boldsymbol{a}}$. And disposal of pollutants in these rivers directly affects $\boldsymbol{G a n g} \overline{\boldsymbol{a}}$ River. No matter how many policies are made and efforts is devoted from the authority sides, positive result cannot be expected unless the polluters are motivated. Volunteer participation on natural capitalism is not possible unless the motivating factor is blended. This motivation is possible only when the seed of spirituality is bowed. When the entire four doors are opened, watershed management can be much easier and possible and be the real example of sustainable development. Being the countries of similar culture, Nepal and India need to give due emphasis on this concept.

Over the past years economic growth of India and Nepal has lifted million people out of the poverty line but this growth is often at the cost of pure environment. Climate of this Bhäratbarșa is threatening for water resources and $\boldsymbol{G a n g} \overline{\boldsymbol{a}}$ and $\boldsymbol{G a u r} \overline{\boldsymbol{l}}$ both are on risk. Himalayan flash flood 2012 of Uttaräkhanda and Annapurna the example of this depleted environmental condition. Business culture of Gang $\overline{\boldsymbol{a}}$ plain is deteriorating day after day. Gap between rich and poor is on increasing trend. Limited people are utilizing unlimited resources on speculative business to drain the residual blood of poor. Growth has not been spiritual and inclusive enough, so that Goddess of wealth is demonstrating her judgment power on natural calamities symbol. Difference on living standard is turning into social conflict. Social harmony is going to be limited as a tourism product and a matter to include on social museums.

The Indian Government has spent crores of rupees on the Gang $\overline{\boldsymbol{a}}$ clean-up drive but the river has become more polluted today than it used to be a decade ago. In fact, the money spent on the river has gone astray and the efforts to keep the Gang $\overline{\boldsymbol{a}}$ pollution-free have come to naught as it absorbs $260 \mathrm{mld}$ sewage daily. After numerous effort government had announced integrated approach to manage the $\boldsymbol{G a n g} \overline{\boldsymbol{a}}$ and announced for National Gang $\overline{\boldsymbol{a}}$ River Basin Authority (NGRBA) Immediate after announcement of NGRBA, people has raised question. Does this River Basin approach apply to only 79\% of $\boldsymbol{G a n g} \overline{\boldsymbol{a}}$ basin, which is in India? Will it include $13 \%$ of Gang $\overline{\boldsymbol{a}}$ basin that is in Nepal, $4 \%$ in Bangaldesh and $4 \%$ in Tibet? What is its relationship with the river systems and with the composite Ganga-Brahmputra-Meghna basin and its consequences? (Krishna,2009). If authority remains on limited work area, problem may come again in future with pollutants carry from remaining $21 \%$ basin area.

However, 'water' is crucial to life and survival, and concerns of sharing and managing this finite element in South Asia has been generating a lot of heat. At one level, are issues that are directly linked to the fact that there is a 'water crisis' looming over the region. It is a reality that usage of water resources has reached or far exceeded the limits of sustainability in most of the countries in South Asia. Rapid growth of population, urbanization and mega cities, industries, mining, intensive irrigation and agriculture has combined with inefficient use of water, to insure that water is fast becoming a scarce resource - both in terms of quantity and quality. This has fuelled conflicts between different uses and users of water, between states within countries, and across countries. With the possibility of devastating impact of climate change, and the severe shortage of freshwater as projected by the Inter-governmental Panel on Climate Change, the situation is likely to take a catastrophic turn. In India alone, gross per capita water availability is stated to decline from around 1,820 cubic meters a year to as low as around 1,140 cubic meters a year in 2050 (IPCC, 4th Assessment Report).

\section{Effectiveness of Spirituality to Preserve Water Resources}

A river belongs to an entire ecosystem, which needs to be protected for the humanity. The Government and the civil society have specific roles in the management of the river. Development and environmental protection cannot be done without combining faith, spiritual approach and science. Decentralization of the functioning of the river basin authority is a primary step. To meet this end the regulatory authority should include representatives of scientists, local residents, environmentalists, saints, priests, pilgrims, in addition to government (S Das, 2011). Spirituality helps in developing self monitoring and control mechanism which is also a low cost mechanism, where social cognitive theory works more effectively. During recent decades an environmental movement that explicitly encompasses religious and spiritual as well as intellectual and political components has been growing exponentially in the United States as well. Sometimes it is called spiritual ecology (Sponsel, L. E., Leslie, E. P., \& Casagrande, D ,2007).

As conservation initiatives were applied in developing nations, whose peoples had very different cultural values and ethics, the relative values of aesthetic and spiritual attachments to landscape and nature began to give way to the absolutes of scientific and economic rationalism. Conscious of the need to gain the support of local communities and to respond to the fact that conservation initiatives often levied significant costs on local communities with few balancing benefits, conservationists embraced materialist perspectives and 
represented the natural world increasingly as comprised of commodities to be sustainably managed. This trend was strengthened by the growing dominance of market-based neoliberal solutions to social issues.

Cultural practices and values develop knowledge that can support the management of ecosystems with special emphasis on ecological resilience (Berkes et al. 2000). Traditional knowledge and practice is increasingly incorporated into the design and management of protected areas and community based resource use regimes. The specific knowledge and experience acquired by local and indigenous communities over centuries can provide significant insights to improve management. Traditional forms of ecosystem management include multiple species management, resource rotation, succession management and patchy resource management that are rarely attempted under conventional modern resource management (Berkes et al. 2000). These approaches can also re-vitalize cultural values and institutions, and help strengthen relationships between people and nature where the forces of modernization and globalization have weakened them. Colding and Folke (2001) advocate for the use of informal institutions, rather than government institutions, as a less expensive option for managing conservation target.

Aspen Institute sets out three principles as the basis for its many recommendations for redefining the nation's concept of infrastructure and putting it on the "Sustainable Path." First, "the traditional definition of water infrastructure must evolve to embrace a broader, more holistic definition of sustainable water infrastructure that includes both traditional man-made water and wastewater infrastructure and natural watershed systems." Second, this principle "should be embraced by all public and private entities involved in water management, and these same entities have a shared role in ensuring their decisions consider and integrate a set of criteria that include environmental, economic and social considerations (the Sustainable Path)." The third principle explicitly states "that a watershed based management approach is required for drinking water, wastewater and storm water services to ensure integrated, sustainable management of water resources."

\section{Conclusion}

Water plays a critical role in sustainable development, given its scarcity; the increasing reliance on shared, international water resources; and the water-intensive nature of sectors identified for economic growth and diversification. No doubt, integrated water resources management combining scientific and technical-based approach is very promising because of public participation-based and explicitly takes care of ecosystem. But what seems to be lacking in this approach is a strong ethical basis, sufficiently rooted in the society. Inception of spirituality in watershed management not only develops motivation among people, it also adds the value on natural capital. Government policies alone cannot manage the watershed, it needs equal contribution from the people and cultural aspects and morality which can reinforce the participation. In the context of countries like Nepal and India, rivers are not only a source of water, they are also a religious asset and also a way for making life for many marginalized citizens. Thus, spiritual capitalism can further strengthen the holiness of these rivers along with the development of inclusive business that can emancipate the standard of the people dependent on water culture.

\section{Journal Papers:}

[1] Das, Subhajyoti. "Cleaning of the Ganga." Journal of the Geological Society of India 78.2 (2011): 124-130.

[2] Ainslie, George. "Specious reward: a behavioral theory of impulsiveness and impulse control." Psychological bulletin 82.4 (1975): 463.

[3] Tversky, Amos, and Daniel Kahneman. "Advances in prospect theory: Cumulative representation of uncertainty." Journal of Risk and uncertainty 5.4 (1992): 297-323.

[4] Weber, Elke U., and Eric J. Johnson. "Psychology and behavioral economics lessons for the design of a green growth strategy." (2012).

[5] Yamin, Farhana. "Biodiversity, ethics and international law." International Affairs (Royal Institute of International Affairs 1944) (1995): 529-546.

\section{Books:}

[1] Sponsel, Leslie E., E. P. Leslie, and D. Casagrande. "Religion, nature and environmentalism." Encyclopedia of Earth. Retrieved on 4.9 (2007).

[2] Weber, Elke U., and Patricia G. Lindemann. "From intuition to analysis: Making decisions with our head, our heart, or by the book." Intuition in judgment and decision making (2007): 191-208.

\section{Working Papers}

[1] Gillingham, Kenneth, Richard G. Newell, and Karen Palmer. Energy efficiency economics and policy. No. w15031. National Bureau of Economic Research, 2009

[2] Krishna G "What is Ganga River Basin Approach," http://www.countercurrent.org, 2009

\section{Theses}

[1] Davis, E. Philip. "A confrontation of economic and theological approaches to "ending poverty" in Africa.", London School of Theology, Brunel University, 2007 